\title{
A PRECARIDADE DO TRABALHO DAS MULHERES NEGRAS QUE SÃO DOMÉSTICAS EM TEMPOS DE PANDEMIA - COVID-rg NO BRASIL.
}

\author{
Lediane Pereira Ramos ${ }^{1}$ \\ Virginia Fernandes Franz ${ }^{2}$
}

RESUMO: Esta pesquisa trata das situações vivenciadas por mulheres negras trabalhadoras domésticas em tempo de pandemia, a covid-ı9 no Brasil, assunto este pouco pesquisado e debatido no campo acadêmico. Historicamente, o trabalho doméstico é uma atividade realizada por mulheres negras, conservando a tradição do passado escravocrata ainda hoje presente no Brasil. Como a atual conjuntura se reflete ainda mais precariamente nesta parcela de trabalhadoras e como os cuidados de contaminação não estão sendo respeitados quando se trata a proteção das domésticas nos lares dos patrões. Como a força de trabalho está sendo agora, explorada em outras vertentes, o abuso de patrões e a pressão que essas mulheres negras sofrem, dentre elas o uso de coação e ameaça no que se refere à continuidade do seu trabalho e a seguridade de seu salário. Mulheres negras e trabalhadoras domésticas no epicentro da pandemia mundial e o poder de dominação de empregadores são os pilares desta discussão.

Palavras-chave: Mulheres. negras. trabalhadoras.

\section{INTRODUÇÃO}

Esta pesquisa procura se aprofundar nos estudos e reflexões sobre as condições de trabalho das mulheres negras domésticas durante a pandemia da covid-ı no Brasil. Se denota a importância desta pesquisa devido aos poucos estudos relacionados a estas

\footnotetext{
${ }^{1}$ Licenciatura plena em história/unemat Graduada em Licenciatura Plena em História pela Universidade do Estado de Mato Grosso (UNEMAT, 2018). Professora efetiva na Secretaria de Estado e Educação de Mato Grosso (SEDUC) desde 2018, atuando na Educação Básica no Ensino Fundamental e Médio. Possuo experiência em docência atuando principalmente na Educação de Jovens e Adultos. Ex-bolsista do CNPQ no Programa Institucional de Bolsas Iniciação à Docência da CAPES/UNEMAT (2014-2018). Possuo experiência na Educação Popular e Movimentos Sociais. Especialista em Docência do Ensino Superior e Teologia pela faculdade ÚNICA. Tutora acadêmica. Mestranda em Educação pela Universidade Federal de Rondonópolis - UFR

E-mail: leidianemaisa@hotmail.com

${ }^{2}$ Graduação em Direito pela Faculdade do Sul de Mato Grosso - Cesur/Facsul (2002). Especialização em Direitos Humanos: Educação e Ressocialização pela Universidade Candido Mendes. Mestranda do Programa de Pós-graduação em Educação pela Universidade Federal de Rondonópolis. Atualmente é assessora jurídica do Ministério Público do Estado do Mato Grosso. Tem experiência na área de Direito, com ênfase em Direito Processual Penal, atuando principalmente nos seguintes temas: educação, direitos humanos, prisão, ressocialização.
} 
mulheres trabalhadoras e como a pandemia vem afetando de forma negativa e precária suas relações de trabalho e de que forma isto está refletindo no seu cotidiano sejam na esfera do trabalho e/ou familiar.

A vulnerabilidade desta categoria está diretamente ligada à falta de proteção social do Estado, abusos e assédios morais, reclusão, desvalorização do trabalho, estigmatização social da sua profissão, condições precárias no que se refere o desenvolvimento de suas tarefas e a baixa remuneração.

Muitas destas mulheres passam mais tempo no local de trabalho e no trajeto até ele, do que na própria casa com familiares, e muitas delas, durante esta pandemia, se veem reclusas na "casa do patrão/oa" muitas vezes obrigadas por eles, ou até mesmo por escolha própria, na tentativa de evitar um possível contágio dentre seus familiares em seus lares. “A plasticidade das práticas racistas adotadas ao longo da história da formação do país possibilita uma vigorosa reelaboração e adaptação aos novos cenários conjunturais decorrentes da pandemia no novo coronavírus” MILANEZ \& VIDA (2020, p. 05). A pandemia mostrando sua face mais monstruosa às populações que historicamente são as mais afetadas por todos os males pelos quais a sociedade enfrentou ao longo da história da humanidade. A fragilidade social enfrentada por mulheres pela sua cor e gênero, atrelada a uma crise epidemiológica.

É preciso lembrar os assédios, os abusos morais e sexuais que essas trabalhadoras estão submetidas, da desvalorização e da falta de segurança sanitária e salarial, jornadas exaustivas e a má remuneração que sempre existiram, desde as longas trajetórias percorridas em transportes públicos lotados no caminho para o trabalho e do trabalho pra casa. Esta dupla, muitas vezes triplas jornadas de trabalho sempre fizeram parte da rotina dessas mulheres, e em face desta "nova realidade", mais uma vez sua vida se torna precária frente a tais perspectivas.

\section{Mulheres Negras Trabalhadoras Domésticas e a precariedade do seu trabalho em tempos de pandemia}

A Pandemia da covid-19 trouxe à tona para a sociedade brasileira, além das mortes que vêm atingindo de uma forma mais agressiva e mortal a população considerada mais 
carente do país, que é a população negra, moradora de locais onde as condições de sobrevivência são precárias ao extremo.

No caso desta pesquisa, debateremos sobre as mulheres negras que têm vivenciado diversas facetas obscuras desta pandemia. Em uma sociedade que já cambaleava pela crise econômica com milhões de desempregados e desalentados Brasil a fora, baixos salários pagos as domésticas e a péssima qualidade de trabalho, a tragédia da pandemia expõe de forma humilhante e dramática as desigualdades presentes no país.

$\mathrm{Na}$ miudeza da vida cotidiana, elas, mulheres negras trabalhadoras já enfrentavam situações complicadas de sobrevivência e bem estar, e agora com essa adversa situação vivida pela sociedade do país, as relações de trabalho são ainda mais prejudiciais a essas mulheres. "O distanciamento social, implica evidentemente, em diversos impactos econômicos e sociais, em especial para aquelas trabalhadoras que atuam de forma autônoma e que dependem do trabalho diário para dali retirarem seu sustento" (IPEA, 2020, p. 13).

As mulheres negras são maioria no trabalho doméstico, conforme dados do IPEA (2020):

\begin{abstract}
As trabalhadoras domésticas representam, hoje, cerca de 6 milhões de mulheres no Brasil, o que corresponde quase $15 \%$ das trabalhadoras ocupadas (10\% das brancas e $18,6 \%$ das negras). O emprego doméstico se revela, portanto, de enorme importância não apenas para um conjunto particular de mulheres, que se encontra nesta profissão uma de suas únicas alternativas de renda, mas também para a organização da sociedade brasileira. (IPEA, 2020, p. 07).
\end{abstract}

As condições de higiene e cuidados básicos de prevenção a covid-ı́ não vem sendo respeitado. Ainda, segundo a avaliação da advogada e pesquisadora do IPEA, Carolina Tokarski (2020), uma das autoras do estudo sobre as Vulnerabilidades das Trabalhadoras Domésticas no Contexto da Pandemia de Covid-ı́ no Brasil, a situação de risco atinge uma grande parcela das trabalhadoras no Brasil. "A grande maioria trabalha sem o fornecimento de máscaras, luvas e álcool em gel. É uma condição de risco na rotina de trabalho considerando a crise sanitária, em que não há fiscalização dos órgãos competentes", observa a pesquisadora, (em documento do IPEA, 2020). O risco de se contaminar é muito grande, no transporte público também no deslocamento até o locar de trabalho, e suas atividades que requerem o contato muito próximo com pessoas, como 
cuidados com crianças e idosos, além da realização de compras em estabelecimentos comerciais, tarefes estas que estão dentre suas funções como empregada doméstica.

Estas mulheres negras, além de sofrerem com diversas situações enfrentadas durante a pandemia, também têm que encarar a dispensa do trabalho doméstico, com muito pouca ou sem nenhuma remuneração, como descrito em documento da CUT (2020):

A pandemia do novo coronavírus (Covid-rg) revelou um lado ainda mais obscuro e vergonhoso de parte da população brasileira que trata suas trabalhadoras domésticas como seres descartáveis, que estão em suas residências apenas para servir. É o triste relato da situação de boa parte das 7,2 milhões de trabalhadoras domésticas, em sua maioria negra, com filhos para criar e baixa escolaridade. É a terceira maior categoria de trabalhadores no Brasil, e mais $73 \%$ vivem na informalidade. Desde o início da pandemia, em março deste ano, aumentaram em cerca de $60 \%$ as denúncias de abuso e falta de pagamentos nos 13 sindicatos estaduais que compõem a Federação Nacional das Trabalhadoras Domésticas (Fenatrad). A reclamação mais comum é a dispensa dessas trabalhadoras sem o devido recolhimento do Fundo de Garantia por Tempo de Serviço (FGTS), da contribuição ao Instituto Nacional do Seguro Social (INSS) e outras verbas rescisórias. Mas há denúncias até de cárcere privado. (Documento da CUT, 2020).

A presidente da Federação Nacional das Trabalhadoras Domésticas

(FENATRAD), Luiza Batista, concedeu uma entrevista à Gênero e Mundo sobre o desrespeito às trabalhadoras domésticas e suas famílias durante a crise da saúde, devido à covid-19. Onde respondeu a questões sobre mulheres negras e suas condições de trabalho e desemprego em tempos de pandemia:

Pergunta - Na pesquisa "Sem parar: o trabalho e a vida das mulheres na pandemia" a maior parte das mulheres que declaram se sentir em risco quanto à sustentação da casa são mulheres negras; entre as mulheres trabalhadoras domésticas, que também são maioria negra, como esse risco tem sido relatado no Sindicato das Domésticas de Pernambuco e na Fenatrad? Luiza Batista - A gente tem recebido cada tipo de denúncia no Sindicato... Primeiro, tem uma parte das trabalhadoras domésticas que entram em contato já demitidas, e agora vão correr atrás dos direitos, mas sem salário, e essa situação é mais parecida ao que já conhecemos. Mas há um grupo das que não foram demitidas e procuram o sindicato porque estão vendo seus direitos violados, se sentem muito sobrecarregados com tarefas que agora são obrigados a acumular, com carga horária maior porque muitas foram praticamente obrigadas a permanecer no local de trabalho, sem ir para a casa. (Em documento FENATRAD, 2020).

Estes patrões estão utilizando todos os artifícios para assegurarem a sua própria segurança e o seu bem estar, sem se preocupar com suas empregadas e as famílias delas.

Como relatado em um dos casos recebidos pela FENATRAD (2020): 


\begin{abstract}
Luiza Batista - Tem uma violação mais grave, que inclui essa: é praticamente um cárcere privado, e que inclusive agora estamos denunciando ao Ministério Público, depois de três trabalhadoras aqui de Pernambuco terem decidido enfrentar os patrões, mesmo sabendo que isso significaria ficarem sem o emprego em que estão. Na pandemia o governo federal criou a Medida Provisória 936, para que empregadores possam suspender contrato de trabalho, e assim o governo garante uma remuneração, que é como um seguro-desemprego. $\mathrm{O}$ que começou a acontecer? Mesmo suspendendo contratos, patrões e patroas exigiam que elas fossem. É um absurdo, mas está acontecendo. Temos aí a violação do direito da trabalhadora ficar em casa e preservar a sua saúde e a da sua família, mas também pessoas burlando as regras da CLT e da Medida Provisória, tirando vantagem da situação em plena pandemia, pois mantêm uma funcionária sem pagar salário, FGTS nem INSS. (Em documento FENATRAD, 2020).
\end{abstract}

As situações enfrentadas por essas mulheres são no mínimo indignantes. A situação da mulher diante da pandemia só piora. "Dirigentes da Federação Nacional das Trabalhadoras Domésticas (FENATRAD) relatam aumento de 6o\% nas denúncias. Patrões não tem vergonha de não pagar salário e mandá-las procurar governo, se quiserem receber. (CUT, 2020). A situação de trabalho destas mulheres em tempos tão incertos são mais preocupantes ainda, existem relatos e situações que beiram a desumanidade, como destacou mais uma vez Cleide Pinheiro Pinto, diretora do sindicato - FENATRAD em Nova Iguaçu no RJ:

"Tivemos de resgatar junto com a polícia uma trabalhadora que conseguiu nos ligar e denunciar o patrão que fechou a porta com chave e disse que ela tinha que passar a quarentena trancada, para não pegar transporte público. Isto é cárcere privado" denuncia diretora da Fenatrad e presidenta do sindicato de Nova Iguaçu (RJ), Cleide Pereira Pinto. (Em documento FENATRAD, 2020).

É de fato uma situação sem precedentes, os patrões estão utilizando até mesmo da força para "garantir" sua saúde diante da pandemia, mas sem levar em conta a saúde física e emocional da sua empregada doméstica. Isto nos remete aos tempos áureos, do escravagismo no Brasil, onde o senhor de escravos fazia o que bem queria com as escravas (os), tratando-as como mercadorias substituíveis, como um produto mesmo.

Em entrevista a PUBLICA (2020), Luiza Batista, vem relatar outra situação enfrentada por uma empregada doméstica:

A organização vem recebendo mais denúncias de mulheres que estão sendo coagidas a trabalhar, sob pena de demissão. As denúncias mais frequentes são de trabalhadoras que "sob coação, ameaça de perder o emprego ou por acharem que elas podem se contaminar no transporte público", estão tendo de pernoitar na casa dos patrões. "Se não houve nenhum acerto no contrato de que a trabalhadora ia pernoitar no emprego, não tem porque o empregador, neste momento, se aproveitar de uma situação de pandemia para obrigar a trabalhadora a pernoitar no emprego", explica. (PUBLICA, 2020). 
$\mathrm{Na}$ crise do covid-I9, se faz necessário assegurar que as vozes, as necessidades e as demandas das mulheres negras trabalhadoras estejam no centro das respostas dos governos, seja municipal, estaduais e/ou federais, é preciso que hajam as políticas públicas de atendimento à população como resposta a esta crise gravíssima, que novamente atingem a parcela excluída da sociedade brasileira, aquela que ficou à margem desde sempre no Brasil, a população trabalhadora negra e pobre deste país.

A crise econômica atrelada a uma pandemia histórica tem se tornado um tsunami na vida dessas mulheres negras, arrasando suas expectativas, pois o trabalho e as condições delas são temerosas, e mais ainda é terrível a situação de quem perde o trabalho nesse período. São diversos relatos Brasil afora de situações que elevam a precariedade das trabalhadoras domésticas no país, como foi descrito em o NEXO (2020):

\footnotetext{
$\mathrm{Na}$ realidade, a crise econômica brasileira tem possibilitado um deslocamento do trabalho formal (com carteira de trabalho) para o informal e de forma perversa: $82 \%$ desses novos postos de trabalho foram ocupados por mulheres negras, grande parte delas no emprego doméstico, sendo $71,2 \%$ desses postos de trabalho informais, $e$ as demais são trabalhadoras por conta própria (ambulantes e cuidadoras). Uma das consequências da crise econômica foi o crescimento do empreendedorismo $e$ as mulheres são a maioria das microempreendoras individuais e, provavelmente, são as "informais" que migraram diante do desemprego para essas novas formas de trabalho. Outro aspecto que devemos chamar atenção é que cerca de $45 \%$ dessas mulheres são responsáveis pela família, e a perda de rendimento afeta seus filhos e dependentes, tornando toda sua família um batalhão de miseráveis. (Em documento do NEXO, 2020).
}

Outros fatores negativos que atingem as mulheres negras em tempos de pandemia se referem ao papel que muitas dessas mulheres têm, como uma dupla ou tripla jornada de trabalho, pois além do emprego doméstico elas ainda precisam cuidar de seus lares, de suas famílias, o que eleva sua rotina a extrema exaustão. "O trabalho de cuidados, ou trabalho reprodutivo, compreende toda uma gama de atividades necessárias para a manutenção física e emocional das pessoas, imprescindível, portanto, para que esses corpos estejam aptos para exercer o trabalho produtivo" (IPEA, 2020 p. 09). Percebe-se que a pandemia tem escancarado à pobreza feminina negra, trazendo a tona o debate nacional e o fardo das tarefas domésticas e a difícil conciliação das mulheres e o cuidado com a família.

Como narram MILANEZ \& VIDA (2020, p. 07), “resumidamente, as políticas de combate à pandemia adotadas estão centradas num eixo supostamente geral e universal que, no fundo, toma como medida as circunstâncias de vida e os recursos acessados pelos 
segmentos brancos da sociedade brasileira". Mas a parcela da população mais pobre do país, não tem e nem terá os mesmos recursos para se manter e aos seus a salvo de possíveis contaminações, pois medidas adotadas por uma parcela branca e elitista da sociedade não será alcançada por estas pessoas. Ainda falando das orientações e medidas:

\begin{abstract}
A exemplo da intensificação da higienização mediante o uso de álcool em gel, água e sabão, a adesão ao isolamento social, o desenvolvimento de atividades laborais em home office, a suspensão de atividades escolares e de parte dos serviços públicos e atividades escolares e de parte dos serviços públicos e atividades econômicas não essenciais, além de outras práticas de distanciamento social, só se mostram efetivamente possíveis para as parcelas brancas da sociedade brasileira. (MILANEZ \& VIDA, 2020, p. o7).
\end{abstract}

Como fica a saúde física e emocional destas mulheres em tempos pandêmicos?

Já que o Estado não parece se importar com suas condições, se antes faltavam-lhes condições adequadas de trabalho e seguros sociais quanto ao desemprego, agora, frente a pandemia é perceptível como se portam as autoridades diante de mais esta tragédia epidêmica que mais uma vez faz vítimas nas classes sociais mais sofridas deste país, conforme MILANEZ \& VIDA (2020):

Numa sociedade historicamente estruturada pelas assimetrias sociorraciais que atravessam inclusive as classes sócias, definindo graus diferenciados de reconhecimento e acesso aos direitos sociais, civis e políticos elementares, as vítimas preferenciais deste genocídio são fundamentalmente, as comunidades negras e urbanas (favelas, invasões, cortiços, vila, ocupações etc) [...] um genocídio relacionado tanto à depuração étnica quanto ao interesse na exploração econômica das terras e dos corpos - sejam das trabalhadoras negras submetidas a um regime de superexposição aos riscos de contágio pela manutenção das atividades do trabalho doméstico nas residências das famílias brancas, sejam dos trabalhadores negros do mercado informal. (MILANEZ \& VIDA, 2020, p. 03 e 04).

A pandemia está expondo essas mulheres a realidades de trabalhos que agora têm outro peso, os afazeres e cuidados domésticos tem outro sentido neste momento, o cotidiano exige muitas tarefas ao longo do dia, desde o amanhecer até o se deitar. Cuidar da casa, cuidar dos filhos, cozinhar, lavar, passar, e ser mãe, filha, esposa, trabalhadora, professora, ser humana. Como está esta relação da mulher consigo mesma, a se ver diante de tantas obrigações e responsabilidades e ao mesmo tempo tão desamparada e humilhada pelo outro?

Como analisa BUTLER (2015, p. 57-58), ao expor o corpo como um "fenômeno social: que está exposto aos outros, e que é vulnerável por definição", a vida aqui é vista e 
instituída por uma normatividade sobre o corpo, se torna "precária" pela instituição da exterioridade ao mundo, por uma aparência fragmentada ou total do contato com o mundo".

As mulheres negras trabalhadoras estão imersas nestes contextos de se colocar a disposição do outro, não por vontade própria, mas por necessidades financeiras, pela sua responsabilidade como provedora do lar. E ao se expor em tempos pandêmicos, expõe-se bem mais que algumas mulheres.

BUTLER (2015) caminha por uma problemática ético-social, fazendo uma reflexão filosófica densa e concentrando sua análise em um diálogo epistemológico acerca da vida, da alteridade, da percepção do outro como sujeito passível do conhecimento, da responsabilidade do "eu" e de "nós" e do reconhecimento e da vulnerabilidade em que o corpo, demarcado por uma ou várias normativas, está inserido.

Neste enquadramento dado a essas mulheres onde suas vidas são expostas como objetos precários, vulneráveis. Em tempos de pandemia, as vidas dessas mulheres estão instituídas por uma normativa sobre o corpo, onde ele (o corpo) se torna precário justamente pela instituição da exterioridade ao mundo, que pelas reflexões de BULTER (2015), quer nos dizer, por uma aparência fragmentada ou total do contato com mundo. É a mulher negra, empregada doméstica que organiza, limpa, passa e faz a comida da elite branca.

No contexto pandêmico do coronavírus, esta vulnerabilidade do trabalho doméstico se amplia em um cenário de dupla vulnerabilidade para estas mulheres. A importância de seu trabalho ainda está atrelada a uma fragilidade no seu funcionamento no que se refere a contrapartida da sociedade em reconhecer o significado que suas funções tem dentro da estrutura trabalhista do país. A crise sanitária nos mostra ainda mais o agravamento da precariedade do trabalho doméstico realizado por mulheres negras no Brasil, estes corpos vulnerabilizados por baixos salários, exaustivas jornadas de trabalho diárias, os assédios no ambiente de trabalho, o próprio racismo, as duplas funções enquanto mulheres, esses corpos que vão para a linha de frente do combate à covid-ı9.

\section{Á guisa de Considerações Finais}


As mulheres domésticas são essenciais na luta contra a covid-ı́, são elas que enfrentam os desafios dos cuidados, na família e no trabalho, e o doméstico não deixa de ser de grande importância. Seja a trabalhadora formal, com carteira assinada, ou aquela informal, que faz diárias em diversas residências durante a semana. A força do trabalho dentre as mulheres cresceu e continua crescendo no país, e dentre elas, a sua grande maioria é negra ou parda.

Essas mulheres estão inseridas em empregos que lhes pagam pouco, que exigem delas o trabalho físico, e assim, sua rotina de oito, dez, doze, dezesseis horas de serviços prestados se torna ainda mais exaustivo e de risco frente a pandemia que assola o país. E todos estes contextos tornam o cotidiano de trabalho delas massacrante e desumano. Nosso país vive uma hierarquia estagnada, na qual o topo é ocupado pelos homens brancos e a base por mulheres negras.

Em tempos pandêmicos essas desigualdades ficam ainda mais evidentes, e as mulheres negras são a principal classe de trabalhadoras que sentirão o efeito econômico. A pandemia coloca as mulheres negras domésticas em condições precárias, suas atividades profissionais estão comprometidas de uma maneira cruel, pois a pandemia atingiu em cheio aquelas que têm origem em segmentos sociais vulneráveis, pertencentes a grupos raciais marginalizados e precariamente ocupadas, sofrendo as consequências desta crise de forma muito mais acentuada. É possível perceber que mais uma vez o Estado coloca essas mulheres às margens de qualquer tipo de assistência e seguridade no que tange a sua empregabilidade e no que se refere estabilidade e proteção em tempos tão adversos para a sociedade em geral. Mais precária ainda é a maneira como patrões e patroas tem se colocado novamente em primeiro lugar, muitas vezes, tomando para si o controle sobre a vida de suas empregadas domésticas. Viver, trabalhar e se proteger da covid-ig para esse grupo específico da sociedade brasileira é mais uma vez um ato de sorte, pois, ou se arrisca a continuar no emprego, ou se vê em meio ao desemprego que já assolava a vida dos brasileiros antes da pandemia.

\section{REFERÊNCIAS}

BUTLER, Judith. "Fundamentos contingentes: o feminismo e a questão do pósmodernismo." Cadernos Pagu, n. II, p. II-42, I998. Tradução de Pedro Maia Soares para versão do artigo "Contigent Foudations: Feminism and the Questiono $f$ Postermodernism”, no Great Phifadelphia Philosophy Consortium, 1999. 
- "Corpos que pesam: sobre os limites discursivos do sex", tradução de Tomaz Tadeu da Silva. In: LOURO, Guacira Lopes (Org.). O corpo edificado. Belo Horizonte: Autêntica Editora, 20oI.

Quadros de Guerra: quando a vida é passível de luto? Tradução de Sérgio Tadeu de Niemeyer Lamarão e Arnaldo Marques da Cunha; revisão de tradução de Marina Vargas; revisão técnica de Carla Rodrigues. I⿳a ed. Rio de Janeiro: Civilização Brasileira, 2015.

CUT. De cárcere privado a falta de pagamentos, o drama das domésticas na pandemia. ROCHA. Rosely. Central Única dos Trabalhadores, 2020. Disponível em: http://cut.org.br/noticias/de-carcere-privado-a-falta-de-pagamentos-o-drama-dasdomesticas-na-pandemia-d6a5 Acesso em 25/o7/2020.

GONZALEZ, Lelia. A Mulher Negra na Sociedade Brasileira - Tendências - Graal: Rio de Janeiro, 1982.

IPEA. Estudo revela situação vulnerável de trabalhadoras domésticas durante a pandemia. Instituto de Pesquisa Econômica Aplicada. 2020. Disponível em http://ipea.gov.br/portal/index.php?option $=$ com_content $\& v i e w=\operatorname{article} \& i d=35807 \&$ catid $=$ 437. Acesso em 30/07/2020.

IPEA. Vulnerabilidade das Trabalhadoras Domésticas no Contexto da Pandemia De Covid-ı No Brasil. IPEA - Instituto de Pesquisa Econômica e Aplicada. PINHEIRO. Luana; TOKARSKI. Carolina; VASCONCELOS. Marcia. Nota Técnica - 2020- JunhoNúmero 75 - Disoc. Disponível em: http://ipea.gov.br/portal/images/stories/PDFs/nota_tecnica/200609_nt_discoc_n_75.pdf Acesso em 02/o8/2020.

FENATRAD. Luiza Batista concede entrevista à Gênero e Número sobre a situação das trabalhadoras domésticas na pandemia. FENATRAD - Federação Nacional das Trabalhadoras domésticas. Fundada em 1997. Disponível em https://fenatrab.org.br/2020/07/31/92/ Acesso em 05/08/2020.

NEXO. A vida das mulheres negras em tempos de pandemia. Hildete Pereira de Melo. 2020. Jornal eletrônico NEXO. Disponível em http://nexojornal.com.br/ensaio/debate/2020/A-vida-das-mulheres-em-tempos-depandemia Acesso em 05/08/2020

PUBLICA. Trabalhadoras domésticas enfrentam coação de patrões durante pandemia. José Cícero da Silva. Disponível em: https://apublica.org/2020/o6/trabalhadorasdomesticas-enfrentam-coacao-de-partoes-durante-pandemia/ Acesso em io/o8/2020. 